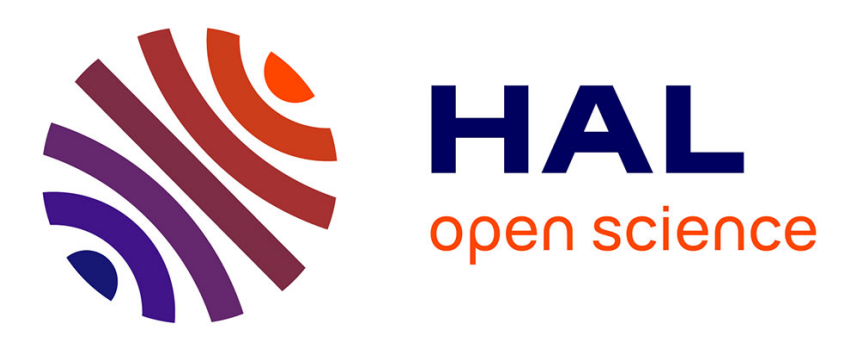

\title{
Density and porosity of the lunar crust from gravity and topography
}

Qian Huang, Mark Wieczorek

\section{To cite this version:}

Qian Huang, Mark Wieczorek. Density and porosity of the lunar crust from gravity and topography. Journal of Geophysical Research. Planets, 2012, 117 (E5), pp.E05003. 10.1029/2012JE004062 . hal02458586

\section{HAL Id: hal-02458586 https://hal.science/hal-02458586}

Submitted on 26 Jun 2020

HAL is a multi-disciplinary open access archive for the deposit and dissemination of scientific research documents, whether they are published or not. The documents may come from teaching and research institutions in France or abroad, or from public or private research centers.
L'archive ouverte pluridisciplinaire HAL, est destinée au dépôt et à la diffusion de documents scientifiques de niveau recherche, publiés ou non, émanant des établissements d'enseignement et de recherche français ou étrangers, des laboratoires publics ou privés. 


\title{
Density and porosity of the lunar crust from gravity and topography
}

\author{
Qian Huang ${ }^{1,2}$ and Mark A. Wieczorek ${ }^{1}$ \\ Received 10 February 2012; revised 9 April 2012; accepted 10 April 2012; published 11 May 2012.
}

[1] Newly obtained gravity and topography data of the Moon, combined with a lithospheric flexure model that considers both surface and subsurface loading, are used to place constraints on the density of the upper crust from a localized spectral admittance analysis. Subsurface loads are found to be relatively unimportant in the highlands, and when subsurface loads are neglected, the best fitting bulk densities for a number of highland regions are found to vary from 2590 to $2870 \mathrm{~kg} \mathrm{~m}^{-3}$, with a mean value of $2691 \mathrm{~kg} \mathrm{~m}^{-3}$. Crustal rock densities estimated from geochemical considerations and global iron and titanium abundances imply somewhat greater densities, which we interpret as porosity affecting the gravity-derived bulk density estimates. The average porosity in the upper few kilometers of crust is calculated to be about $7.7 \%$, which is consistent with porosity estimates of impact-fractured meteorites and terrestrial impact craters.

Citation: Huang, Q., and M. A. Wieczorek (2012), Density and porosity of the lunar crust from gravity and topography, J. Geophys. Res., 117, E05003, doi:10.1029/2012JE004062.

\section{Introduction}

[2] Density and porosity are fundamental parameters in a large range of geophysical investigations. As examples, crustal thickness modeling requires knowledge of the density of the crust [e.g., Neumann et al., 1996; Wieczorek and Phillips, 1998; Hikida and Wieczorek, 2007; Ishihara et al., 2009], and lithospheric flexure calculations require not only the density of the crust, but also the density of the load [e.g., Forsyth, 1985; McGovern et al., 2002; Belleguic et al., 2005; Wieczorek, 2008]. Impact crater scaling laws have an important dependence on porosity [e.g., Ivanov, 2006], the interpretation of seismic wave velocities depends upon both density and porosity [e.g., Gardner et al., 1974; O'Connell and Budiansky, 1974], and thermal conductivity is strongly dependent on porosity [Warren and Rasmussen, 1987]. Remote estimates of crustal density can be used to place constraints on the composition of planetary crusts. Furthermore, crustal porosity is a critical parameter for studies of subsurface aquifers [Clifford, 1993].

[3] Continuing sample, remote sensing and geophysical analyses show that there are large lateral and vertical variations in composition of the lunar crust, and by inference, density. Global surface geochemical data from the Clementine and Lunar Prospector missions indicate that there are at least three distinct geochemical provinces on the Moon,

\footnotetext{
${ }^{1}$ Institut de Physique du Globe de Paris, Sorbonne Paris Cité, SaintMaur-des-Fossés, France.

${ }^{2}$ Shanghai Astronomical Observatory, Chinese Academy of Sciences, Shanghai, China.

Corresponding author: Q. Huang, Shanghai Astronomical Observatory, Chinese Academy of Sciences, 80 Nandan Rd., 200030 Shanghai, China. (huangqian@shao.ac.cn)

Copyright 2012 by the American Geophysical Union. 0148-0227/12/2012JE004062
}

each possessing a unique geologic evolution [Jolliff et al., 2000]. Heat-producing and incompatible elements are highly concentrated within the Procellarum KREEP Terrane, along with the dense mare basaltic lava flows. The surrounding highlands crust is highly anorthositic in composition, and remote sensing data of central peaks in this terrane suggest that the crust either becomes more mafic with depth, or is heterogeneous in composition [e.g., Tompkins and Pieters, 1999; Wieczorek and Zuber, 2001; Cahill et al., 2009]. The interior of the South Pole-Aitken basin has a highly noritic composition [Lucey et al., 1995; Pieters et al., 1997, 2001], and this is often interpreted to represent the composition of more dense lower-crustal materials.

[4] In this paper, newly obtained gravity and topography data of the Moon are analyzed to place constraints on the density of the highlands crust. A localized spectral admittance analysis was performed at several locations and these spectra were interpreted in terms of a geophysical model that includes both surface and subsurface loads. In addition to bulk crustal densities, constraints on the elastic thicknesses of the lithosphere and the importance of subsurface loads are obtained. Using the known compositions of Apollo samples, an empirical correlation is found between the average grain densities of lunar rocks and their iron and titanium abundances. Using these independent density estimates in combination with the gravity-based bulk density determinations, the porosity of the upper lunar crust is estimated.

\section{Bulk Density From Gravity and Topography}

[5] Crustal density is an important parameter in modeling the observed gravity field of a planet. In this study, we make use of the fact that the linear transfer function between gravity and topography depends primarily upon crustal density and elastic thickness when these data are expressed in spherical harmonics [e.g., Wieczorek, 2007]. In modeling the 
relationship between gravity and topography, we consider the case where the lithosphere is treated as a thin elastic spherical shell on which both surface and subsurface loads are emplaced. We employ an adapted version of the thin elastic spherical shell model of Turcotte et al. [1981], and include subsurface loads that are perfectly correlated or perfectly anticorrelated with surface loads. This approach has been used previously by McNutt [1983] to estimate elastic thickness on Earth, and by McGovern et al. [2002] and Belleguic et al. [2005] to estimate both crustal density and elastic thickness on Mars.

[6] Using the known topography, theoretical gravity fields are calculated as a function of crustal density $\rho_{c}$, crustal thickness $T_{c}$, elastic thickness $T_{e}$, and a parameter $L$ that defines the importance of surface and subsurface loading. $L$ is here defined as the ratio of the mass of material added within the lithosphere as a subsurface load to the sum of the magnitudes of the masses of surface and subsurface loads. As the subsurface load can have both positive and negative values, $L$ is bounded between \pm 1 . Though partially correlated surface and subsurface loads are known to affect the relationship between gravity and topography [e.g., Macario et al., 1995; Wieczorek, 2007; Kirby and Swain, 2009], the admittance function for partially correlated loads lies between the end-member cases of correlated and anticorrelated loads used in this study.

[7] The wavelength-dependent relationship between gravity and topography is quantified by the degree-dependent admittance and correlation functions

$$
\begin{gathered}
Z(l)=\frac{S_{g h}(l)}{S_{h h}(l)}, \\
\gamma(l)=\frac{S_{g h}(l)}{\sqrt{S_{h h}(l) S_{g g}(l)}},
\end{gathered}
$$

where $S_{g g}, S_{h h}$, and $S_{g h}$, represent the autopower and crosspower spectra of the gravity and topography, respectively (for a review, see Wieczorek [2007]). The cross-power spectrum of the radial gravity and topography is defined as

$$
S_{g h}=\sum_{m=-l}^{l} g_{l m} h_{l m},
$$

where $g_{l m}$ and $h_{l m}$ are the real spherical harmonic coefficients of the radial gravity and topography, respectively. By varying the parameters of the geophysical model, the best fitting model to the observed admittance can be obtained.

[8] Though our model admittance function depends upon elastic thickness, crustal density, and the magnitude of subsurface loads, the model admittance approaches that expected for uncompensated surface topography at high degrees (i.e., short wavelengths). In particular, the asymptotic value at high degrees is proportional to the density of the crust and is given by $Z=2 \pi \rho G$. This equation is simply the Bouguer gravity formula, and is a consequence of the fact that the amount of lithospheric flexure decreases with increasing spherical harmonic degree and that gravitational anomalies at depth from subsurface loads become increasingly attenuated with increasing spherical harmonic degree. If high-enoughresolution gravity and topography were available, it would in principle be straightforward to estimate the upper crustal density from the high-degree asymptotic value of the admittance.

[9] Given the expectation that crustal density will vary laterally across the lunar surface, localized spectral admittance and correlation functions were calculated by windowing the free-air gravity and surface topography with the band-limited localization windows of Wieczorek and Simons [2005, 2007] and Simons et al. [2006]. The localization windows are constructed to minimize the signal arising exterior to an angular radius $\theta_{0}$ for a given spectral bandwidth $L_{\text {win }}$, and we use a single localization window that concentrates more than $99 \%$ of its power in the region of interest. We note that simple windowing functions that have a constant value within a spherical cap, and that are zero exterior to this region, contain a significant amount of high-frequency power beyond the first spectral lobe [Wieczorek and Simons, 2005].

[10] As a result of the spatial localization of the spectral estimates, the spectral resolution of the spectral estimates is decreased. In particular, a localized spectral estimate at degree $l$ will contain information in the global data set from degrees $l-L_{\text {win }}$ to $l+L_{\text {win }}$. In order to neglect the influence of possible low-degree rotational and tidal contributions of degree 2, which are not taken into account in our model, localized admittances and correlations are analyzed only between degrees $L_{\text {win }}+3$ and $L_{\text {data }}-L_{\text {win }}$, where $L_{\text {data }}$ corresponds to the maximum degree of the utilized gravity model. The assumption that surface and subsurface loads are either perfectly correlated or anticorrelated implies that the localized spectral correlation function should be nearly 1 or -1 . Furthermore, we implicitly assume that the geophysical parameters do no vary laterally within the analysis region.

[11] The best fitting model and uncertainties are determined using a multistep estimation procedure. First, best fitting model parameters are estimated by minimizing the reduced $\chi^{2}$ function

$$
\frac{\chi^{2}}{\nu}\left(\rho_{c}, T_{e}, L\right)=\frac{1}{\nu} \sum_{l=l \min }^{l \max }\left(\frac{Z_{l}^{o b s}-Z_{l}^{c a l}\left(\rho_{c}, T_{e}, L\right)}{\sigma_{l}^{o b s}}\right),
$$

where $\nu$ is the number of degrees of freedom $\left(l_{\max }-\right.$ $l_{\min }-3$ ), and where $l_{\max }$ and $l_{\min }$ are the maximum and minimum spherical harmonic degrees used in the misfit function. $Z_{l}^{o b s}$ is the observed admittance and $Z_{l}^{\text {cal }}$ is the modeled admittance, both of which are windowed in exactly the same manner. A simple estimate of the admittance uncertainty, $\sigma_{l}^{o b s}$, is first used by assuming that the localized gravity and topography coefficients for a given degree are linearly related and that the lack of correlation is a result of random noise in the gravity [e.g., Simons et al., 1997]. This initial approach assumes inherently that adjacent power spectrum estimates are uncorrelated, but this is not the case when using localized spectrum estimates [Wieczorek and Simons, 2007]. After determining the best fit parameters, the uncertainty estimate for the degree-dependent localized admittance was improved upon using a Monte Carlo approach: Given the best fitting model parameters and known gravity field error spectrum, numerous realizations of a synthetic gravity field were created as

$$
g_{l m}=Z_{l} h_{l m}+I_{l m},
$$



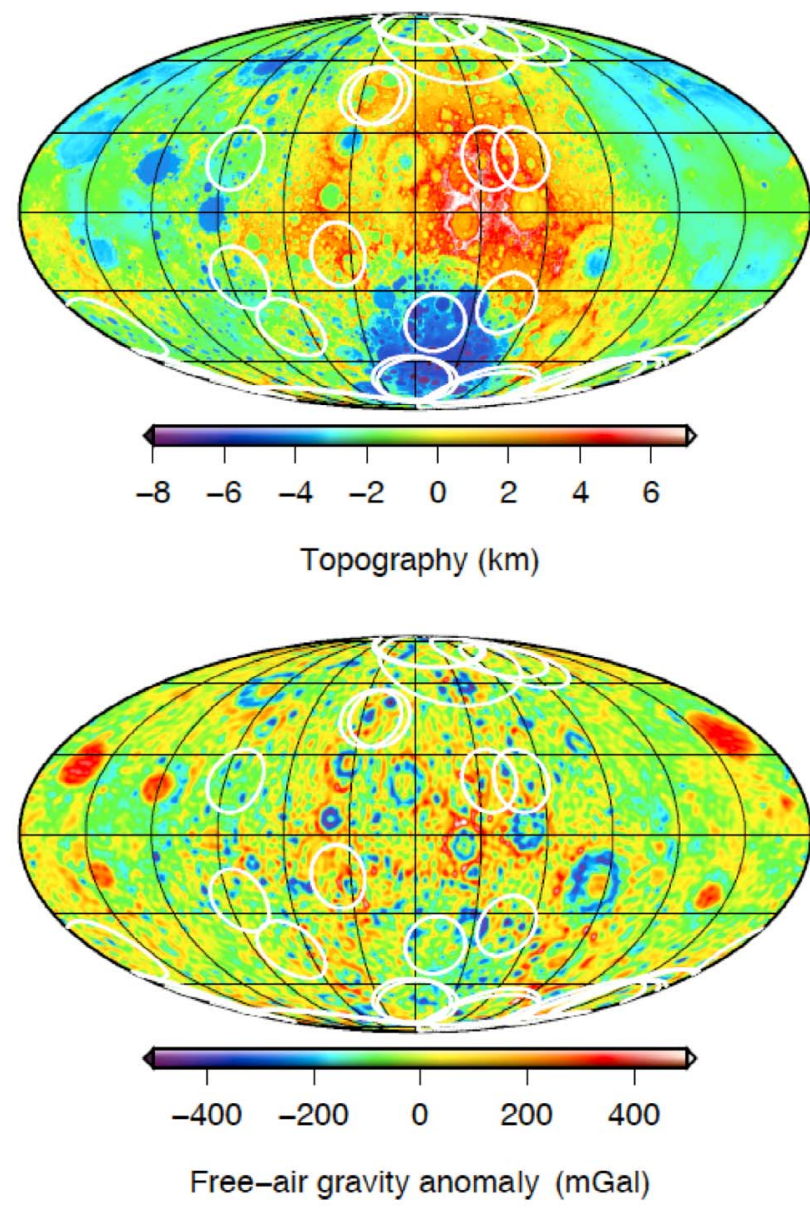

Figure 1. Laser altimeter-derived topography from the Lunar Reconnaissance Orbiter mission and Kaguya radial gravity (SGM100i) plotted on a reference sphere of $1738 \mathrm{~km}$. The rotational contribution to the gravity and topography has been removed for clarity. Both images are shown in a global Mollweide projection centered over the farside hemisphere on the $180^{\circ}$ meridian, and grid lines are spaced at $30^{\circ}$ intervals. The white circles correspond to the regions analyzed in Tables 1 and 2 .

where $Z_{l}$ is the best fitting global linear transfer function, and $I_{l m}$ is the gravitational noise. The gravitational noise was assumed to be a random Gaussian process with a variance given by

$$
\sigma_{l m}^{2}=\frac{S_{I I}(l)}{2 l+1},
$$

where $S_{I I}$ is the gravitational error spectrum. By definition, the noise is uncorrelated with the surface topography. We then compared the synthetic admittances with noise to the noise-free ones in order to obtain an improved estimate of the expected uncertainty in the admittance,

$$
\bar{\sigma}_{m c}(l)=\sqrt{\frac{\sum_{i=1}^{N}\left[Z_{l}^{\text {bestfit }}-Z_{l}^{m c}(i)\right]^{2}}{N}},
$$

where $N$ is the number of random realizations, $Z_{l}^{m c}$ is the admittance for a given Monte Carlo realization with noise, and $Z_{l}^{\text {bestfit }}$ is the noise-free value. The reduced $\chi^{2}$ was recalculated with these improved uncertainties, and by using the distribution of $Z_{l}^{m c}$, the probability that this value could have a value less than the estimated value by chance was determined. The allowable range of model parameters was then estimated using the $67 \%(1 \sigma)$ and $95 \%(2 \sigma)$ confidence intervals.

\section{Bulk Density Results}

[12] High-resolution topography data are currently available from several recent spacecraft missions, such as Chang'e-1 [Ping et al., 2009], Kaguya [Araki et al., 2009], and Lunar Reconnaissance Orbiter [Smith et al., 2010]. Since 2007, global gravitational models that include for the first time data collected over the farside hemisphere have been made available by the Japanese mission Kaguya [Namiki et al., 2009]. In this paper, we make use of the most recent topographic data obtained from the Lunar Reconnaissance Orbiter mission, which is expressed as a 720 degree and order spherical harmonic model [Smith et al., 2010]. The Kaguya gravity model SGM100i is used, which has been determined from Kaguya and historical tracking data (Figure 1). Though the gravity model is expressed to degree and order 100, the gravity coefficients are valid globally only to about degree and order 70 [Matsumoto et al., 2010; Goossens et al., 2011]. Nevertheless, shorter wavelengths can be analyzed locally in regions where the gravity coverage is good and the signal is strong.

[13] In any localized spectral analysis, a tradeoff exists between the spatial size of the window and the spectral resolution of the power spectrum estimates. For our analyses, we used a localization window with an angular radius of $12^{\circ}$ (i.e., a diameter of about $720 \mathrm{~km}$ ) and a spectral bandwidth $L_{\text {win }}$ equal to 21 (see section 2). For a maximum degree of 100 for the gravity field, this allows us to analyze localized power spectrum estimates from degree 21 to 79 . Given that the quality of the Kaguya gravity field is laterally heterogeneous, the maximum localized spherical harmonic degree utilized was in practice less than this. This window size and spectral bandwidth allows us to avoid averaging over adjacent geologic provinces, while retaining a sufficient number of localized admittance estimates in order to give reasonable error estimates on our geophysical model parameters. In order to increase the degree range of the localized admittance function, we also investigated in some regions windows with an angular radius of $20^{\circ}$ and a spectral bandwidth of 13 . Future high-resolution gravity models from the mission GRAIL (Gravity Recovery And Interior Laboratory) will eventually allow one to use smaller localization windows with higher spectral bandwidths.

[14] Since our geophysical model requires the localized spectral correlation function between gravity and topography to be nearly unity, we manually searched for regions amenable to analysis. For each point on a $1^{\circ}$ by $1^{\circ}$ global grid, we calculated the average radius of the region within the localization window, we downward continued the gravitational field to this reference radius, the resulting gravity and topography were multiplied by the localization window, and the localized autopower and cross-power spectra of these 
Table 1. Summary of Bulk Density, Elastic Thickness, Loading Parameter, and Porosity Results

\begin{tabular}{|c|c|c|c|c|c|c|c|c|c|}
\hline $\begin{array}{l}\text { Region } \\
\text { Number }\end{array}$ & $\begin{array}{l}\text { Region } \\
(\mathrm{E}, \mathrm{N})\end{array}$ & $\theta_{0}$ & $\begin{array}{c}\text { Modeled Degree } \\
\text { Range }\end{array}$ & $\begin{array}{c}T_{c} \\
(\mathrm{~km})\end{array}$ & $\begin{array}{c}T_{e} \\
(\mathrm{~km})\end{array}$ & $L$ & $\begin{array}{c}\rho_{c} \\
\left(\mathrm{~kg} \mathrm{~m}^{-3}\right)\end{array}$ & $\begin{array}{c}\rho_{F e-T i} \\
\left(\mathrm{~kg} \mathrm{~m}^{-3}\right)\end{array}$ & $\begin{array}{l}\text { Porosity } \\
\quad(\%)\end{array}$ \\
\hline 1 & $\left(195^{\circ}, 80^{\circ}\right)$ & $12^{\circ}$ & $38-54$ & 47.7 & $26_{-26}^{+\infty}$ & $0.15_{-0.30}^{+0.11}$ & $2960_{-280}^{+310}$ & 2884 & $-2.6(-13.4$ to 7.1$)$ \\
\hline 2 & $\left(200^{\circ}, 80^{\circ}\right)$ & $12^{\circ}$ & $38-54$ & 48.1 & $19_{-19}^{+\infty}$ & $0.12_{-0.27}^{+0.21}$ & $3010_{-260}^{+170}$ & 2888 & $-4.2(-10.1$ to 4.8$)$ \\
\hline 3 & $\left(230^{\circ}, 20^{\circ}\right)$ & $12^{\circ}$ & $35-47$ & 68.8 & $19_{-19}^{+\infty}$ & $0.16_{-0.39}^{+0.15}$ & $2720_{-180}^{+250}$ & 2897 & $6.1(-2.5$ to 12.3$)$ \\
\hline 4 & $\left(45^{\circ},-85^{\circ}\right)$ & $12^{\circ}$ & $40-70$ & 46.5 & $5_{-5}^{+\infty}$ & $0.18_{-0.60}^{+0.05}$ & $2640_{-120}^{+400}$ & 2907 & $9.2(-4.6$ to 13.3$)$ \\
\hline 5 & $\left(110^{\circ},-45^{\circ}\right)$ & $12^{\circ}$ & $40-70$ & 45.0 & $9_{-9}^{+\infty}$ & $0.07_{-0.52}^{+0.24}$ & $\begin{array}{l}2850_{-150}^{+350} \\
\end{array}$ & 2937 & $3.0(-8.9$ to 8.1$)$ \\
\hline 6 & $\left(144^{\circ},-16^{\circ}\right)$ & $12^{\circ}$ & $38-54$ & 57.6 & $9_{-9}^{+\infty}$ & $0.13_{-0.53}^{+0.10}$ & $2660_{-100}^{+410}$ & 2907 & $8.5(-5.6$ to 11.9$)$ \\
\hline 7 & $\left(210^{\circ}, 70^{\circ}\right)$ & $20^{\circ}$ & $32-60$ & 53.0 & $11_{-7}^{+11}$ & $0.04_{-0.29}^{+0.11}$ & $2840_{-90}^{+160}$ & 2899 & $2.0(-3.5$ to 5.1$)$ \\
\hline 8 & $\left(215^{\circ}, 20^{\circ}\right)$ & $12^{\circ}$ & $45-60$ & 74.6 & $30_{-30}^{+\infty}$ & $-0.15_{-0.23}^{+0.38}$ & $2690_{-130}^{+120}$ & 2898 & $7.2(3.0$ to 11.7$)$ \\
\hline 9 & $\left(225^{\circ},-35^{\circ}\right)$ & $12^{\circ}$ & $32-60$ & 51.7 & $30_{-30}^{+\infty}$ & $0.10_{-0.33}^{+0.19}$ & $2700_{-170}^{+360}$ & 2902 & $7.0(-5.4$ to 12.8$)$ \\
\hline
\end{tabular}

fields were determined. Regions where the localized spectral correlation was greater than 0.95 over at least 10 contiguous degrees were retained for further analysis.

[15] For each retained region, the range of geophysical model parameters that could fit the observed localized admittance was obtained as described in section 2. For each set of model parameters, a forward gravity model was constructed and windowed in a similar manner as the actual data. The crustal density, elastic thickness and loading parameter were treated as free parameters, whereas the other rheological parameters were set to fixed values. Crustal density $\rho_{c}$ was allowed to vary between 2500 and $3300 \mathrm{~kg} \mathrm{~m}^{-3}$, the elastic thickness $T_{e}$ varied from 0 to $150 \mathrm{~km}$, and the loading parameter $L$ varied between -0.5 and 0.5 . It is well known that the crustal thickness cannot be obtained uniquely from admittance analyses, so for each analysis region we set this value equal to the average value predicted by the crustal thickness model of Garrick-Bethell et al. [2010] (see Tables 1 and 2). The mantle density $\rho_{m}$ was fixed to $3360 \mathrm{~kg} \mathrm{~m}^{-3}$ [e.g., Hikida and Wieczorek, 2007], Young's modulus E was set to $10^{11} \mathrm{~Pa}$, and a value of 0.25 was used for Poisson's ratio. The sensitivity of our results to these assumed values is small and will be discussed later. By varying the crustal density, elastic thickness, and loading parameter over all possible values, the best fitting model was obtained, along with their $1 \sigma$ and $2 \sigma$ confidence intervals. Though previous analyses have attempted to constrain the elastic thickness at various regions on the Moon by using spectral techniques [e.g., Crosby and McKenzie, 2005; Audet, 2011], none of these analyses have treated the crustal density as a free parameter.

[16] Out of about 100 retained regions, 9 gave results with reasonable error bars for the bulk density (see Table 1). Figure 1 shows that the locations of these regions are primarily on the farside hemisphere in the highlands and the South Pole-Aitken basin. The small number of analysis regions on the nearside is partially a result of the large localization window sizes that make it difficult to avoid signals from the mascon basins and maria. Example best fitting localized admittance and correlation spectra are shown in Figure 2 for a representative farside highlands region. In this example, the admittance is modeled from degrees 32

Table 2. Summary of Bulk Density, Elastic Thickness, and Porosity Results When Subsurface Loads are Neglected

\begin{tabular}{|c|c|c|c|c|c|c|c|c|}
\hline $\begin{array}{l}\text { Region } \\
\text { Number }\end{array}$ & $\begin{array}{l}\text { Region } \\
(\mathrm{E}, \mathrm{N})\end{array}$ & $\theta_{0}$ & $\begin{array}{c}\text { Modeled Degree } \\
\text { Range }\end{array}$ & $\begin{array}{c}T_{c} \\
(\mathrm{~km})\end{array}$ & $\begin{array}{c}T_{e} \\
(\mathrm{~km})\end{array}$ & $\begin{array}{c}\rho_{c} \\
\left(\mathrm{~kg} \mathrm{~m}^{-3}\right)\end{array}$ & $\begin{array}{c}\rho_{F e-T i} \\
\left(\mathrm{~kg} \mathrm{~m}^{-3}\right)\end{array}$ & $\begin{array}{c}\text { Porosity } \\
(\%)\end{array}$ \\
\hline 1 & $\left(10^{\circ},-45^{\circ}\right)$ & $12^{\circ}$ & $42-70$ & 41.3 & $20_{-12}^{+\infty}$ & $2670_{-60}^{+90}$ & 2922 & $8.6(5.5$ to 10.7$)$ \\
\hline 2 & $\left(30^{\circ},-85^{\circ}\right)$ & $12^{\circ}$ & $40-70$ & 46.8 & $21_{-9}^{+\infty}$ & $2600_{-50}^{+70}$ & 2906 & $10.5(8.1$ to 12.2$)$ \\
\hline 3 & $\left(35^{\circ},-85^{\circ}\right)$ & $12^{\circ}$ & $40-70$ & 46.7 & $16_{-6}^{+\infty}$ & $2630_{-60}^{+60}$ & 2906 & 9.5 (7.4 to 11.6$)$ \\
\hline 4 & $\left(45^{\circ},-85^{\circ}\right)$ & $12^{\circ}$ & $40-70$ & 46.5 & $12_{-6}^{+\infty}$ & $2690_{-60}^{+90}$ & 2907 & $7.5(4.4$ to 9.5$)$ \\
\hline 5 & $\left(95^{\circ}, 20^{\circ}\right)$ & $12^{\circ}$ & $57-70$ & 40.6 & $60_{-51}^{+\infty}$ & $2690_{-50}^{+90}$ & 2898 & $7.2(4.1$ to 8.9$)$ \\
\hline 6 & $\left(95^{\circ},-25^{\circ}\right)$ & $12^{\circ}$ & $42-60$ & 41.6 & $16_{-6}^{+\infty}$ & $2610_{-60}^{+80}$ & 2935 & $11.1(8.3$ to 13.1$)$ \\
\hline 7 & $\left(110^{\circ},-45^{\circ}\right)$ & $12^{\circ}$ & $40-70$ & 45.0 & $8_{-2}^{+2}$ & $2820_{-50}^{+70}$ & 2937 & $4.0(1.6$ to 5.7$)$ \\
\hline 8 & $\left(144^{\circ},-16^{\circ}\right)$ & $12^{\circ}$ & $38-54$ & 57.6 & $14_{-6}^{+\infty}$ & $2700_{-90}^{+150}$ & 2907 & $7.1(2.0$ to 10.2$)$ \\
\hline 9 & $\left(155^{\circ}, 45^{\circ}\right)$ & $12^{\circ}$ & $30-44$ & 58.0 & $22_{-7}^{+\infty}$ & $2590_{-80}^{+90}$ & 2914 & $11.1(8.0$ to 13.9$)$ \\
\hline 10 & $\left(160^{\circ}, 45^{\circ}\right)$ & $12^{\circ}$ & $30-42$ & 58.6 & $18_{-7}^{+\infty}$ & $2650_{-90}^{+130}$ & 2910 & $8.9(4.5$ to 12.0$)$ \\
\hline 11 & $\left(177^{\circ},-69^{\circ}\right)$ & $12^{\circ}$ & $47-69$ & 24.9 & $9_{0}^{+\infty}$ & $2630_{-70}^{+140}$ & 2992 & $12.1(7.4$ to 14.4$)$ \\
\hline 12 & $\left(182^{\circ},-70^{\circ}\right)$ & $12^{\circ}$ & $47-70$ & 25.1 & $15_{-8}^{+\infty}$ & $2720_{-100}^{+180}$ & 2992 & 9.1 (3.1 to 12.4$)$ \\
\hline 13 & $\left(191^{\circ},-43^{\circ}\right)$ & $12^{\circ}$ & $40-56$ & 23.9 & $20_{-9}^{+\infty}$ & $2730_{-110}^{+180}$ & 3041 & $10.2(4.3$ to 13.8$)$ \\
\hline 14 & $\left(210^{\circ}, 70^{\circ}\right)$ & $20^{\circ}$ & $32-60$ & 53.0 & $11_{-2}^{+3}$ & $2860_{-50}^{+40}$ & 2899 & $1.3(0.0$ to 3.1$)$ \\
\hline 15 & $\left(215^{\circ}, 20^{\circ}\right)$ & $12^{\circ}$ & $45-60$ & 74.6 & $15_{-7}^{+\infty}$ & $2660_{-40}^{+60}$ & 2898 & $8.2(6.1$ to 9.6$)$ \\
\hline 16 & $\left(227^{\circ},-35^{\circ}\right)$ & $15^{\circ}$ & $40-60$ & 53.9 & $13_{0}^{+\infty}$ & $2650_{-40}^{+60}$ & 2896 & 8.5 (6.4 to 9.9$)$ \\
\hline 17 & $\left(230^{\circ}, 20^{\circ}\right)$ & $12^{\circ}$ & $35-47$ & 68.8 & $63_{-47}^{+\infty}$ & $2800_{-30}^{+80}$ & 2897 & $3.3(0.6$ to 4.4$)$ \\
\hline 18 & $\left(252^{\circ},-74^{\circ}\right)$ & $12^{\circ}$ & $47-57$ & 39.3 & $18_{-18}^{+\infty}$ & $2620_{-70}^{+290}$ & 2925 & $10.4(0.5$ to 12.8$)$ \\
\hline 19 & $\left(255^{\circ},-77^{\circ}\right)$ & $12^{\circ}$ & $49-60$ & 38.9 & $13_{-13}^{+\infty}$ & $2630_{-90}^{+290}$ & 2929 & $10.2(0.3$ to 13.3$)$ \\
\hline 20 & $\left(260^{\circ}, 75^{\circ}\right)$ & $12^{\circ}$ & $42-58$ & 47.4 & $22_{-15}^{+\infty}$ & $2670_{-40}^{+130}$ & 2913 & 8.3 (3.9 to 9.7$)$ \\
\hline 21 & $\left(270^{\circ}, 70^{\circ}\right)$ & $12^{\circ}$ & $40-60$ & 46.6 & $7_{-6}^{+9}$ & $2870_{-180}^{+210}$ & 2915 & $1.5(-5.7$ to 7.7$)$ \\
\hline 22 & $\left(325^{\circ},-70^{\circ}\right)$ & $12^{\circ}$ & $40-60$ & 47.7 & $35_{-23}^{+\infty}$ & $2670_{-70}^{+110}$ & 2899 & $7.9(4.1$ to 10.3$)$ \\
\hline 23 & $\left(335^{\circ},-70^{\circ}\right)$ & $12^{\circ}$ & $40-60$ & 48.1 & $18_{-11}^{+\infty}$ & $2720_{-90}^{+160}$ & 2897 & $6.1(0.6$ to 9.2$)$ \\
\hline 24 & $\left(340^{\circ},-70^{\circ}\right)$ & $12^{\circ}$ & $44-60$ & 48.4 & $13_{-7}^{+\infty}$ & $2750_{-120}^{+240}$ & 2896 & $5.0(-3.2$ to 9.2$)$ \\
\hline 25 & $\left(345^{\circ},-65^{\circ}\right)$ & $12^{\circ}$ & $40-60$ & 46.3 & $19_{-9}^{+\infty}$ & $2710_{-60}^{+100}$ & 2895 & $6.4(2.9$ to 8.5$)$ \\
\hline 26 & $\left(350^{\circ},-65^{\circ}\right)$ & $12^{\circ}$ & $44-56$ & 46.9 & $13_{-8}^{+\infty}$ & $2700_{-110}^{+220}$ & 2894 & $6.7(-0.9$ to 10.5$)$ \\
\hline
\end{tabular}




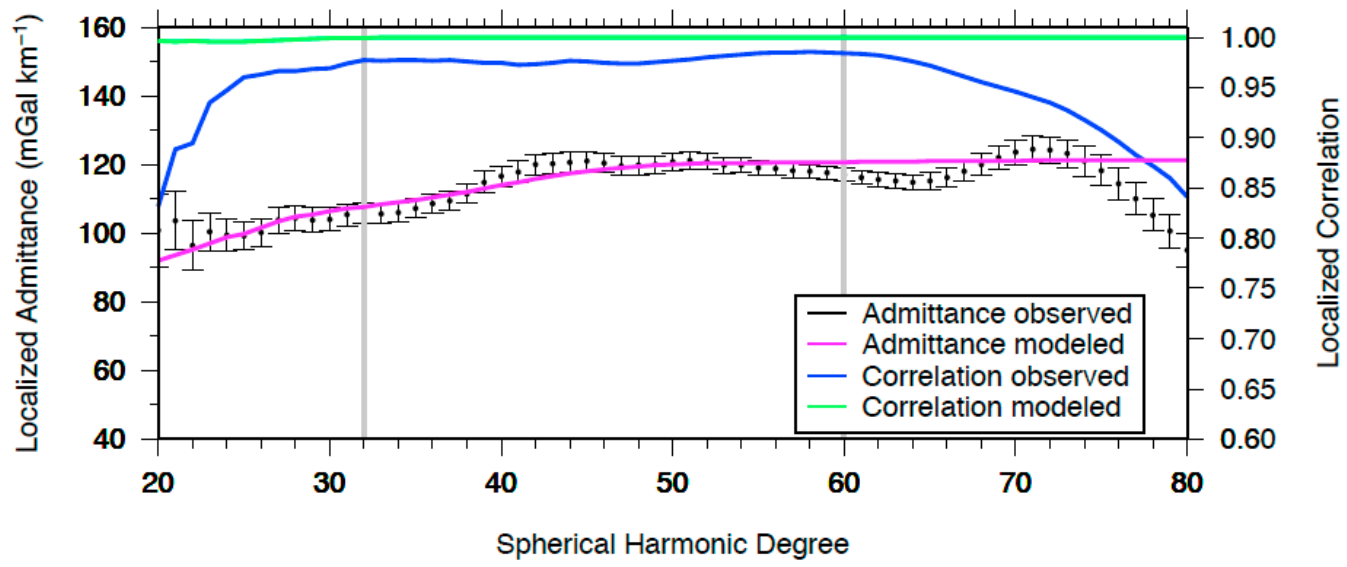

Figure 2. Localized admittance and correlation spectra for a representative region over the farside highlands and the best fitting geophysical model. The localization window is centered at $210^{\circ} \mathrm{E}, 70^{\circ} \mathrm{N}$ with $\theta_{0}=20^{\circ}$ and $L_{\text {win }}=13$, and the localized admittance is modeled only where the localized correlations are close to unity between degrees 32 and 60 .

to 60 where the correlation spectrum possesses values greater than 0.95 . The spectral correlation function sharply decreases beyond degree 60 , which is a result of the sparse four-way Doppler tracking on the lunar farside, especially at mid to high northern latitudes [Matsumoto et al., 2010]. The geophysical model is seen to be capable of fitting the entire degree range where the correlation is high.

[17] Figure 3 shows the minimum misfit for this same region as a function of each varied geophysical parameter. With a $67 \%$ confidence interval, the crustal density is constrained to lie between 2750 to $3000 \mathrm{~kg} \mathrm{~m}^{-3}$, possessing a best fit value of $2840 \mathrm{~kg} \mathrm{~m}^{-3}$. The best fit elastic thickness is $11 \mathrm{~km}$, with an allowable range from 4 to $22 \mathrm{~km}$. The misfit function of the load ratio is approximately centered over zero, and indicates that subsurface loads are not required to fit the admittance. Nevertheless, the best fitting subsurface load is found to be about $4 \%$ of the total load, and could contribute up to $25 \%$ of the total load $(1 \sigma)$.

[18] Our results for all 9 regions show that the best fitting densities vary from about 2640 to $3010 \mathrm{~kg} \mathrm{~m}^{-3}$, with individual uncertainties of about $\pm 200 \mathrm{~kg} \mathrm{~m}^{-3}$. Best fit elastic thicknesses are between 5 and $30 \mathrm{~km}$, but for most cases, any value greater than 0 can fit the data. The best fit loading parameter $L$ varies from -0.15 to 0.18 , with a tendency toward positive values. Nevertheless, the uncertainties for each region allow both positive and negative values, and the misfit plots are approximately centered over zero.

[19] From our analyses that consider both surface and subsurface loads, the elastic thickness is not well constrained and the uncertainties on the crustal density are somewhat high. Since our results show that subsurface loads are not required to fit the observed localized admittances, we have performed similar inversions using the assumption that only surface loads are present (i.e., $L=0$ ) in an attempt to place tighter constraints on these parameters. Under this assumption, 26 regions are found to be both amenable to analysis and to have well constrained densities. As summarized in Table 2, the best fit bulk densities for these regions lie between 2590 and $2870 \mathrm{~kg} \mathrm{~m}^{-3}$, with an average of $2691 \mathrm{~kg}$ $\mathrm{m}^{-3}$. Most of the density analyses have uncertainties that are

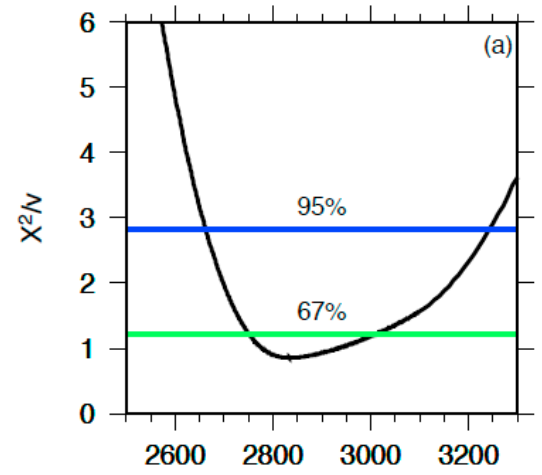

Crustal Density $\left(\mathrm{kg} \mathrm{m}^{-3}\right)$
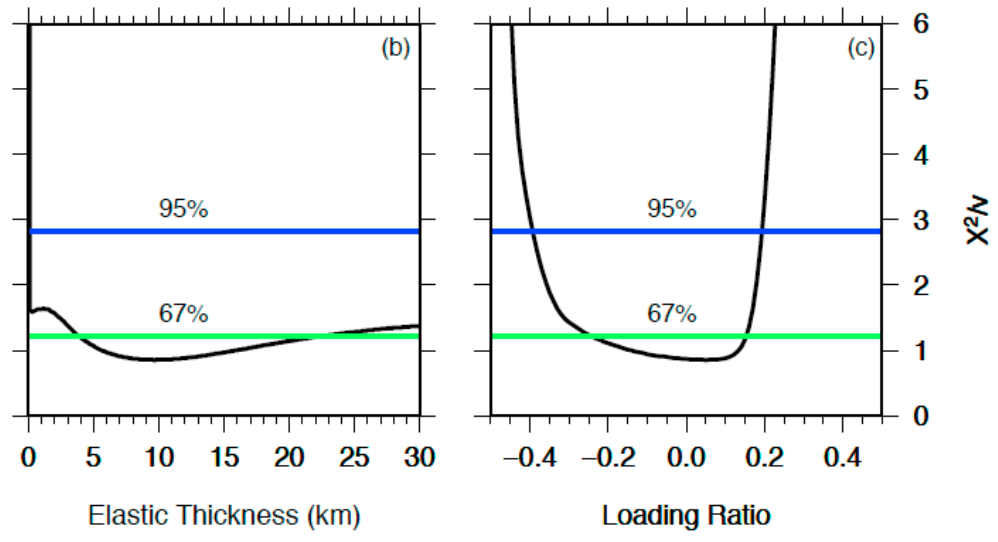

Figure 3. Minimum misfits for the region shown in Figure 2 as a function of (a) crustal density, (b) elastic thickness, and (c) loading parameter. The green and blue lines represent the $1 \sigma$ and $2 \sigma$ confidence intervals, respectively. 


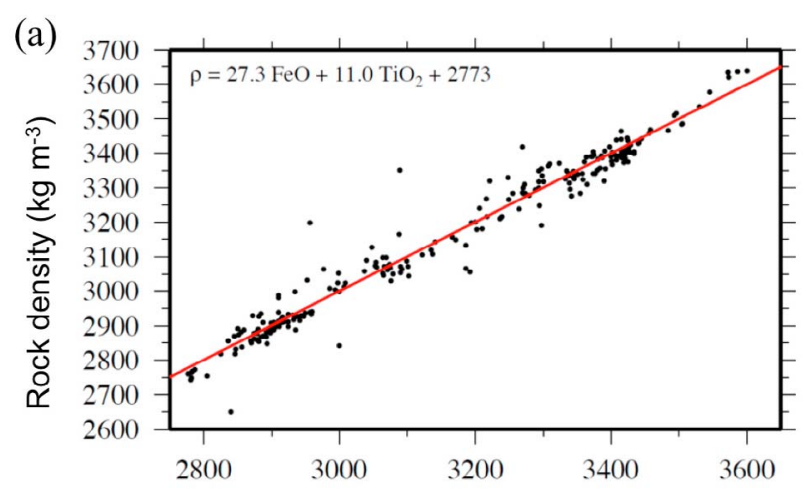

(b)

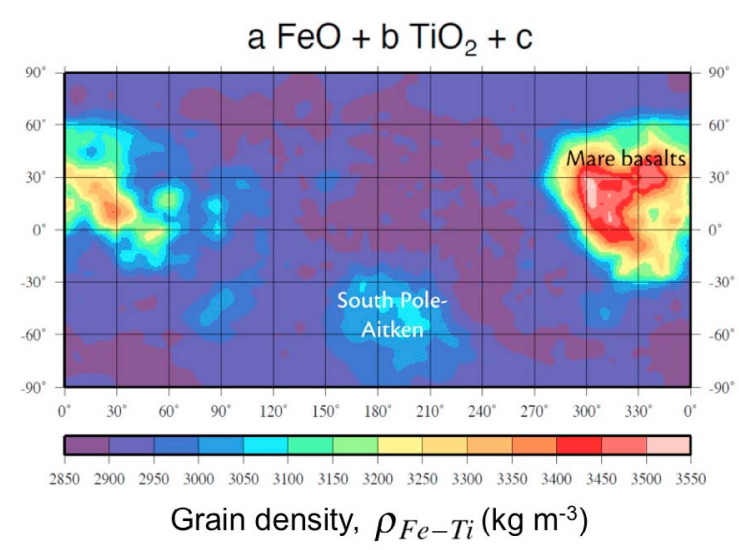

Figure 4. (a) Estimated pore-free grain densities of lunar samples as a function of the combined weighted concentrations of $\mathrm{FeO}$ and $\mathrm{TiO}_{2}$ in wt. \%. (b) Global estimates of the pore-free surface density derived from the relationship in Figure $4 \mathrm{a}$ combined with the iron and titanium abundances obtained from the Lunar Prospector gamma ray spectrometer. This map is presented in a simple cylindrical projection centered on the farside hemisphere. The high densities on the nearside hemisphere correspond to the mare basalts, and the slight enhancement in density in the southern farside highlands corresponds to the South Pole-Aikten basin.

about $\pm 100 \mathrm{~kg} \mathrm{~m}^{-3}$, and although the elastic thickness estimates are somewhat variable, those analyses with the smallest uncertainties have values close to $10 \mathrm{~km}$.

[20] We have verified that the crustal densities presented in Tables 1 and 2 are robust in several ways. First, we have tested crustal thicknesses that differ by $\pm 15 \mathrm{~km}$ with respect to our reference model, and found that our crustal densities only varied by $\pm 50 \mathrm{~kg} \mathrm{~m}^{-3}$ and that the loading ratio only varied by about \pm 0.04 . Given that the admittance does not depend upon crustal thickness in the short-wavelength asymptotic limit, the insensitivity of crustal thickness on our results should not be too surprising. The mantle density is relatively well constrained as a result of the Moon's high moment of inertia factor [e.g., Khan et al., 2007]. To test our results to the sensitivity of the chosen value, we have varied our mantle density by $\pm 50 \mathrm{~kg} \mathrm{~m}^{-3}$ with respect to our reference value and found that the inverted crustal density varied by less than $\pm 10 \mathrm{~kg} \mathrm{~m}^{-3}$. Slightly different window sizes and neighboring locations were used, as were different gravity models, such as SGM100h [Matsumoto et al., 2010]. The inversion results for these analyses were found to be similar to those presented here. Higher-resolution gravity data over the nearside hemisphere from the LP150Q model [Konopliv et al., 2001] did not improve in any significant way our inversions over the nearside as a result of the strong regularization constraint that was used to obtain this global gravitational model with no farside coverage.

\section{Grain Density and Crustal Porosity}

[21] Based on the 26 localized admittance analyses that neglect subsurface loads (Table 2), the average bulk density of the lunar highlands crust is estimated to be $2694 \mathrm{~kg} \mathrm{~m}^{-3}$. This value is somewhat lower than the values of 2860 and $2930 \mathrm{~kg} \mathrm{~m}^{-3}$ that have been advocated for the upper and lower crust of the Moon, respectively, based on the mineralogy of central peaks [e.g., Wieczorek et al., 2006; Wieczorek and Zuber, 2001]. Given that the upper crust of the Moon is expected to be highly fractured [e.g., Toksöz et al., 1974] and that the gravity analyses are only sensitive to the bulk density, and not grain density, we attribute this difference to the presence of porosity in the crust. In this section, we develop an independent method to estimate the grain density of the crust based on analyses of Apollo samples and orbital remote sensing data, and then compare these to the values obtained from the gravity analyses to determine the crustal porosity.

[22] We start with the lunar rock compositions as summarized in Wieczorek et al. [2006, Tables A3.1-A3.9, A3.11, and A3.12]. A standard CIPW mineralogical norm was performed [Best, 2002, Appendix B] for each bulk chemical composition, and the pore-free grain density of the rock was estimated using the known density of the component minerals. After neglecting 4 analyses that were not amenable to the mineralogical norm, 236 rock densities were obtained that are representative of the ferroan anorthosite, Mg suite, alkali suite, KREEP basalt, impact melt, granulitic breccia, mare basalt and volcanic glass compositions.

[23] The iron and titanium abundances of lunar samples are known to vary dramatically, and this is simply a consequence of the variable quantities of mafic phases and the mineral ilmenite. We performed a least squares analysis between the estimated rock density and these two oxides and found a very good empirical correlation, as shown in Figure 4a [see also Solomon, 1978; Wieczorek and Phillips, 1997]:

$$
\rho_{\mathrm{Fe}-\mathrm{Ti}}=27.3 \mathrm{FeO}+11.0 \mathrm{TiO}_{2}+2773 .
$$

[24] The root mean square misfit with respect to the best fitting line is only $45 \mathrm{~kg} \mathrm{~m}^{-3}$, and only 8 of the 236 samples have misfits greater than $100 \mathrm{~kg} \mathrm{~m}^{-3}$. Those samples with the greatest misfits correspond to atypical compositions (such as spinel troctolites, dunites, and granites), and since these compositions are not expected to be volumetrically important in the lunar crust, knowledge of only the abundance of iron and titanium as measured from orbit are necessary to obtain a very good estimate of the pore-free crustal density. Though it is not strictly appropriate to apply this correlation to the lunar regolith, as this contains glass that is not taken into account in our mineralogical norm, the regolith is only about $10 \mathrm{~m}$ thick [e.g., Fa and Wieczorek, 2012] and is volumetrically insignificant with respect to our gravity analyses. Nevertheless, the bulk composition of the regolith should be representative 


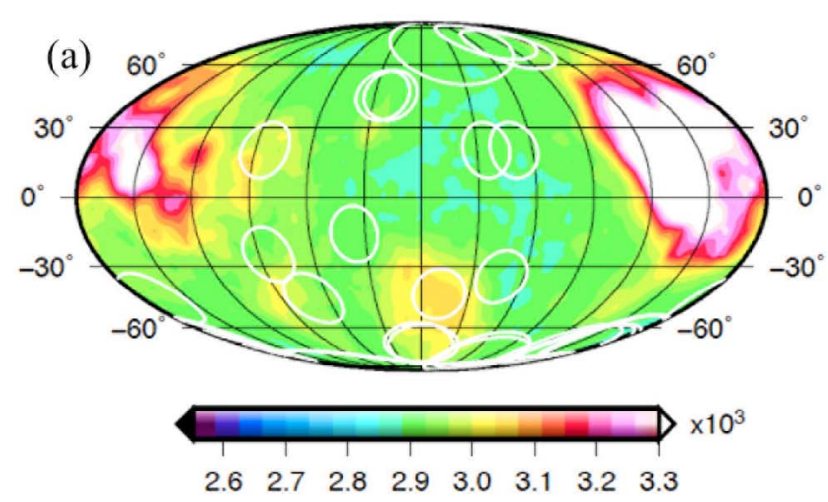

Grain Density $\left(\mathrm{kg} \mathrm{m}^{-3}\right)$

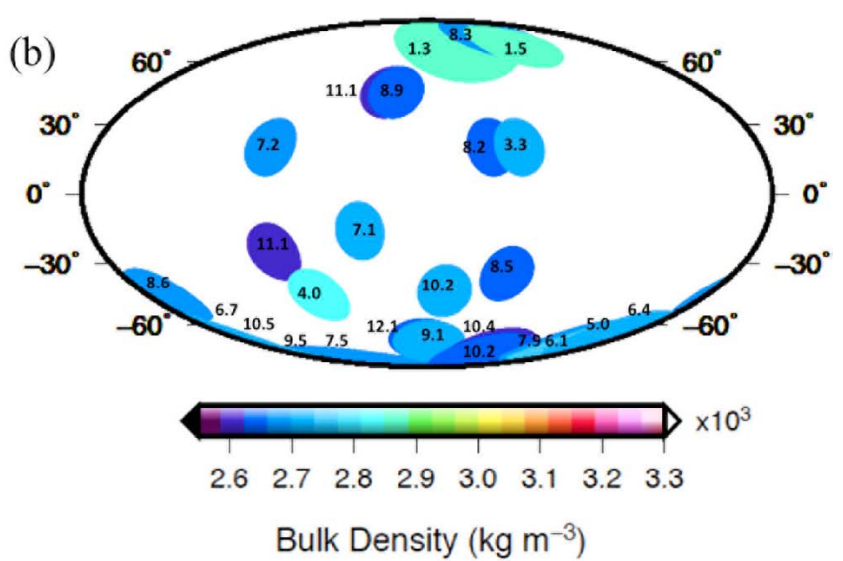

Figure 5. Grain densities and estimated bulk densities. (a) Global grain density plot showing the regions analyzed in Table 2, and (b) plot of our inverted bulk densities from gravity and topography. Numbers in Figure $5 \mathrm{a}$ are the best fitting porosities. Both Figures $5 \mathrm{a}$ and $5 \mathrm{~b}$ have the same projection as Figure 1.

of the composition of the underlying crust, except in regions where the composition changes rapidly, such as at the boundaries between the highlands and maria.

[25] We note that Kiefer et al. [2012] have directly measured the grain densities of 13 lunar rocks using helium pycnometry and bead techniques. When compared with grain densities estimated by mineralogical norm approaches, the difference was found to be about $20 \mathrm{~kg} \mathrm{~m}^{-3}$, which is less than the variation about our best fit empirical correlation. For the samples analyzed in their study, the RMS difference between the measured grain densities and the estimates from our correlation is $64 \mathrm{~kg} \mathrm{~m}^{-3}$, which is smaller than the uncertainty in the majority of our gravity-based bulk density determinations. Though our estimated grain densities correlate best with $\mathrm{TiO}_{2}$ and $\mathrm{FeO}$, we note that the pairs $\mathrm{TiO}_{2}$ and $\mathrm{Al}_{2} \mathrm{O}_{3}$, and $\mathrm{TiO}_{2}$ and $\mathrm{CaO}$, also correlate well with grain density, but with larger RMS misfits of 67 and $122 \mathrm{~kg} \mathrm{~m}^{-3}$, respectively.

[26] Lunar Prospector gamma ray spectrometer global iron and titanium abundances [Prettyman et al., 2006] are used to estimate the pore-free grain density of the lunar crust in Figure $4 \mathrm{~b}$. The Lunar Prospector data products used here have a $5^{\circ}$ spatial resolution $(\sim 150 \mathrm{~km})$, which is more than sufficient for comparison to our admittance analyses that cover regions several times larger. As shown in this map, the pore-free density of the lunar crust is expected to vary laterally, from about $2860 \mathrm{~kg} \mathrm{~m}^{-3}$ in the highlands, to about $3000 \mathrm{~kg} \mathrm{~m}^{-3}$ in the South Pole-Aitken basin, to up to $3500 \mathrm{~kg}$ $\mathrm{m}^{-3}$ for the high-titanium mare basalts on the nearside hemisphere. Variations of only $100 \mathrm{~kg} \mathrm{~m}^{-3}$ are expected within the relatively homogeneous farside highlands. Figure 5a shows the locations of our analysis regions superposed on a map of estimated grain density, and for comparison, Figure $5 \mathrm{~b}$ shows our estimated bulk densities for the same regions.

[27] Assuming that the composition of the lunar surface is representative of the underlying crust, the porosity is calculated for each region in Tables 1 and 2. Negative porosities are unphysical, but are quoted in order to aid in interpreting the significance of these values. In calculating the porosity, we have ignored the inherent uncertainty in the estimated grain density from equation (8), given that the uncertainty of
$45 \mathrm{~kg} \mathrm{~m}^{-3}$ of this relationship is considerably less than the bulk density uncertainties from the gravity and topography analyses. Using all those analyses that neglect subsurface loads, the porosity is found to be $7.7 \pm 2.8 \%$, with permissible values $(1 \sigma)$ from 0 to $14 \%$ (Figure 6 ).

[28] Given that the admittance at the highest degrees in our analyses is not affected significantly by subsurface loads, and that the lithosphere is effectively rigid at these short wavelengths, our bulk crustal densities and porosities should be considered representative over the same depth scale as the topographic surface load, which is on the order of 2 to $3 \mathrm{~km}$. Though significant porosity is likely to exist beneath these depths, the present analysis cannot provide any quantitative constraints on this magnitude of this value. Apollo seismic data show that seismic velocities gradually increase with depth in the crust [e.g., Khan and Mosegaard, 2002;

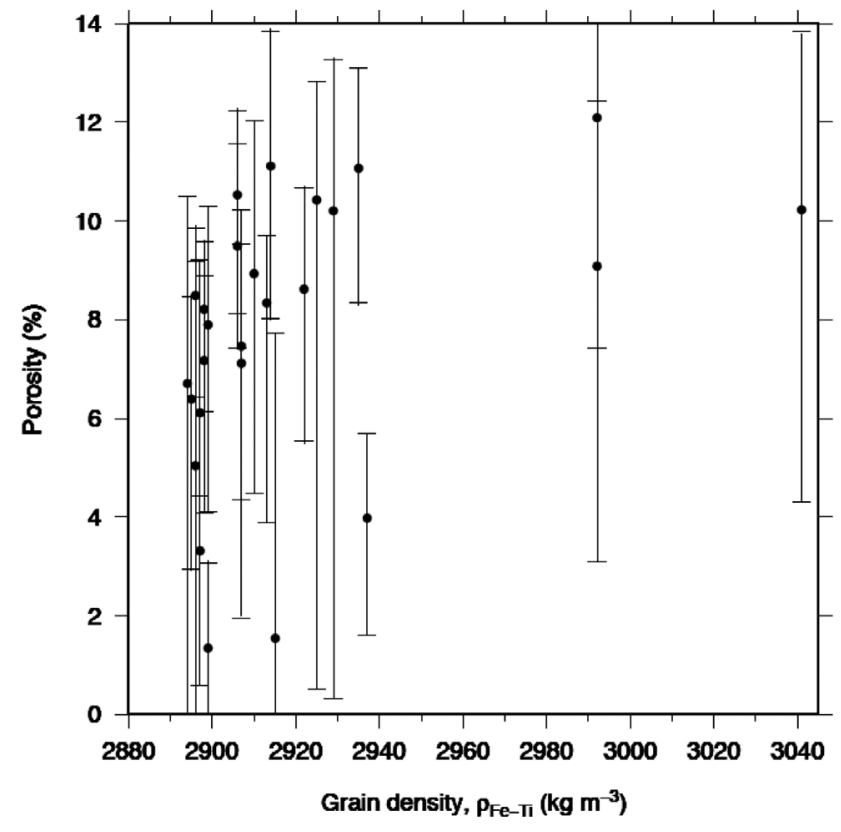

Figure 6. Crustal porosity as a function of the estimated pore-free grain density. 
Gagnepain-Beyneix et al., 2006], perhaps all the way into the upper mantle, and this has been attributed to the closure of impact-generated porosity with increasing lithostatic pressure [Toksöz et al., 1972; Simmons et al., 1973]. This picture is generally consistent with measurements of seismic velocity of lunar samples as a function of confining pressure [Todd et al., 1973; Wang et al., 1973; Simmons et al., 1975]. The Apollo seismic measurements have been used to suggest that crustal porosity may decrease exponentially with depth, perhaps with an $e$-folding length scale of about $6 \mathrm{~km}$ [Binder and Lange, 1980].

[29] Our estimated porosities are broadly consistent with what is known about the porosities of extra-terrestrial materials and impact-fractured terrestrial impact craters. Ordinary chondrite falls have porosities of $7.4 \pm 5.3 \%$ [Consolmagno et al., 2008, and references therein], and lunar meteorites have measured porosities of $7.5 \pm 3.2 \%$ [Warren, 2001] and $6.5 \pm 4.7 \%$ [Kiefer et al., 2012]. Apollo samples collected at the surface can have significantly higher porosities $(\sim 20 \%$ [see Warren, 2001; Kiefer et al., 2012]), but these porosities are unlikely to be representative of the materials underlying the impact-processed regolith. Though shock appears to compact and remove porosity in meteorites, a baseline porosity of about $5-10 \%$ was found for even the most highly shocked chondrite meteorites [Consolmagno et al., 2008]. Most of the void space in these meteorites is not due to macroscopic pores, but is rather a result of shock-related microfractures that cut grain boundaries. Based on the gravity anomaly associated with the Reis impact crater, about 5\% porosity is predicted in the rocks that underlay this crater [Pohl et al., 1977], which is similar to the meteorite porosities.

\section{Conclusions}

[30] Localized spectral admittance analyses using newly obtained gravity and topography of the Moon show that it is possible to invert for the density of the lunar crust. When neglecting subsurface loads, an average density of $2691 \pm$ $71 \mathrm{~kg} \mathrm{~m}^{-3}$ is found for the farside highlands, and based on geochemical constraints and global remote sensing data, the porosity of the upper few kilometers of the crust is calculated to be $7.7 \pm 2.8 \%$. This porosity is similar to that found in both lunar and chondritic meteorites, and in analogy to the meteorite results, we suggest that this porosity is a result of microfractures created by the cumulative effect of billions of years of impact generated shock waves.

[31] The presence of significant crustal porosity over kilometer scale depths has many implications for lunar evolution. First, thermal conductivity is known to be highly sensitive to porosity [Warren and Rasmussen, 1987], and reduced thermal conductivities in the upper crust imply hotter temperatures at depth. Second, impact crater scaling laws depend upon the porosity of the target material [Holsapple and Housen, 2007], and for several kilometers of fractured crust, we would expect craters smaller than a few tens of kilometers to form in a slightly porous material. The change from porous to nonporous scaling has important implications for the relationship between impact crater and asteroid size-frequency distributions [Ivanov, 2006; Le Feuvre and Wieczorek, 2011]. Finally, porosity in the upper crust would reduce the strength of the lithosphere. Using future data from
NASA's Gravity Recovery and Interior Laboratory (GRAIL) mission, it will be possible to extend the results of this analysis globally.

[32] Acknowledgments. The authors would like to thank Francis Nimmo for editorial handling of the manuscript and Walter Kiefer and an anonymous reviewer for constructive reviews and comments that helped improve the manuscript. The localized spherical harmonic analyses were performed using SHTOOLS, available at http://shtools.ipgp.fr. This work was supported by a CNES (Centre National d'Etudes Spatiales) doctoral fellowship, the Chinese National Science Foundation (NSFC 10973031), and Chinese National High-Tech Project 2010AA122206. This is IPGP contribution 3282

\section{References}

Araki, H., et al. (2009), Lunar global shape and polar topography derived from Kaguya-LALT laser altimetry, Science, 323(5916), 897-900 doi:10.1126/science. 1164146 .

Audet, P. (2011), Directional wavelet analysis on the sphere: Application to gravity and topography of the terrestrial planets, J. Geophys. Res., 116, E01003, doi:10.1029/2010JE003710.

Belleguic, V., P. Lognonné, and M. Wieczorek (2005), Constraints on the Martian lithosphere from gravity and topography data, J. Geophys. Res., 110, E11005, doi:10.1029/2005JE002437.

Best, M. G. (2002), Igneous and Metamorphic Petrology, 2nd ed., Blackwell Sci., Oxford, U. K.

Binder, A. B., and M. A. Lange (1980), On the thermal history, thermal state, and related tectonism of a Moon of fission origin, J. Geophys. Res., 85(B6), 3194-3208, doi:10.1029/JB085iB06p03194.

Cahill, J. T. S., P. G. Lucey, and M. A. Wieczorek (2009), Compositional variations of the lunar crust: Results from radiative transfer modeling of central peak spectra, J. Geophys. Res., 114, E09001, doi:10.1029/ 2008JE003282.

Clifford, S. M. (1993), A model for the hydrologic and climatic behavior of water on Mars, J. Geophys. Res., 98, 10,973-11,016, doi:10.1029/ 93JE00225.

Consolmagno, G. J., D. T. Britt, and R. J. Macke (2008), The significance of meteorite density and porosity, Chem. Erde, 68(1), 1-29, doi:10.1016/ j.chemer.2008.01.003

Crosby, A., and D. McKenzie (2005), Measurements of the elastic thickness under ancient lunar terrain, Icarus, 173, 100-107, doi:10.1016/j.icarus. 2004.07.017.

Fa, W., and M. A. Wieczorek (2012), Regolith thickness over the lunar nearside: Results from Earth-based $70-\mathrm{cm}$ Arecibo radar observations, Icarus, 218(2), 771-787, doi:10.1016/j.icarus.2012.01.010.

Forsyth, D. (1985), Subsurface loading and estimates of the flexural rigidity of continental lithosphere, J. Geophys. Res., 90, 12,623-12,632, doi:10.1029/JB090iB14p12623.

Gagnepain-Beyneix, J., P. Lognonné, H. Chenet, D. Lombardi, and T. Spohn (2006), A seismic model of the lunar mantle and constraints on temperature and mineralogy, Phys. Earth Planet. Inter., 159, 140-166, doi:10.1016/j.pepi.2006.05.009.

Gardner, G. H. F., L. W. Gardner, and A. R. Gregory (1974), Formation velocity and porosity-The diagnostic basics for stratigraphic traps, Geophysics, 39(6), 770-780, doi:10.1190/1.1440465.

Garrick-Bethell, I., F. Francis, and M. A. Wieczorek (2010), Structure and formation of the lunar farside highlands, Science, 330(6006), 949-951, doi: $10.1126 /$ science. 1193424

Goossens, S., et al. (2011), Lunar gravity field determination using SELENE same-beam differential VLBI tracking data, J. Geod., 85(4), 205-228, doi:10.1007/s00190-010-0430-2

Hikida, H., and M. A. Wieczorek (2007), Crustal thickness of the Moon: New constraints from gravity inversions using polyhedral shape models, Icarus, 192(1), 150-166, doi:10.1016/j.icarus.2007.06.015.

Holsapple, K. A., and K. R. Housen (2007), A crater and its ejecta: An interpretation of Deep Impact, Icarus, 187(1), 345-356, doi:10.1016/j. icarus.2006.08.029.

Ishihara, Y., S. Goossens, K. Matsumoto, H. Noda, H. Araki, N. Namiki, H. Hanada, T. Iwata, S. Tazawa, and S. Sasaki (2009), Crustal thickness of the Moon: Implications for farside basin structures, Geophys. Res. Lett., 36, L19202, doi:10.1029/2009GL039708.

Ivanov, B. A. (2006), Earth/Moon impact rate comparison: Searching constraints for lunar secondary/primary cratering proportion, Icarus, 183(2), 504-507, doi:10.1016/j.icarus.2006.04.004

Jolliff, B. L., J. J. Gillis, L. A. Haskin, R. L. Korotev, and M. A. Wieczorek (2000), Major lunar crustal terranes: Surface expressions and crustmantle origins, J. Geophys. Res., 105(E2), 4197-4216, doi:10.1029/ 1999JE001103. 
Khan, A., and K. Mosegaard (2002), An inquiry into the lunar interior: A nonlinear inversion of the Apollo lunar seismic data, J. Geophys. Res., 107(E6), 5036, doi:10.1029/2001JE001658.

Khan, A., J. A. D. Connolly, J. Maclennan, and K. Mosegaard (2007), Joint inversion of seismic and gravity data for lunar composition and thermal state, Geophys. J. Int., 168, 243-258, doi:10.1111/j.1365-246X.2006. 03200.x

Kiefer, W. S., R. J. Macke, D. Britt, A. J. Irving, and G. Consolmagno (2012), The density and porosity of lunar rocks, Geophys. Res. Lett., 39, L07201, doi:10.1029/2012GL051319.

Kirby, J. F., and C. J. Swain (2009), A reassessment of spectral $T_{e}$ estimation in continental interiors: The case of North America, J. Geophys. Res. 114, B08401, doi:10.1029/2009JB006356.

Konopliv, A. S., S. W. Asmar, and E. Carranza (2001), Recent gravity models as a result of the Lunar Prospector mission, Icarus, 150(1), 1-18, doi:10.1006/icar.2000.6573.

Le Feuvre, M., and M. A. Wieczorek (2011), Nonuniform cratering of the Moon and a revised crater chronology of the inner Solar System, Icarus, 214(1), 1-20, doi:10.1016/j.icarus.2011.03.010.

Lucey, P. G., G. J. Taylor, and E. Malaret (1995), Abundance and distribution of iron on the Moon, Science, 268(5214), 1150-1153, doi:10.1126/ science.268.5214.1150

Macario, A., A. Malinverno, and W. F. Haxby (1995), On the robustness of elastic thickness estimates obtained using the coherence method, J. Geophys. Res., 100, 15,163-15,172, doi:10.1029/95JB00980.

Matsumoto, K., et al. (2010), An improved lunar gravity field model from SELENE and historical tracking data: Revealing the farside gravity features, J. Geophys. Res., 115, E06007, doi:10.1029/2009JE003499.

McGovern, P. J., S. C. Solomon, D. E. Smith, M. T. Zuber, M. Simons, M. A. Wieczorek, R. J. Phillips, G. A. Neumann, O. Aharonson, and J. W. Head (2002), Localized gravity/topography admittance and correlation spectra on Mars: Implications for regional and global evolution, J. Geophys. Res., 107(E12), 5136, doi:10.1029/2002JE001854.

McNutt, M. K. (1983), Influence of plate subduction on isostatic compensation in northern California, Tectonics, 2, 399-415, doi:10.1029/ TC002i004p00399.

Namiki, N., et al. (2009), Farside gravity field of the Moon from four-way Doppler measurements of SELENE (Kaguya), Science, 323(5916), 900-905, doi:10.1126/science. 1168029

Neumann, G. A., M. T. Zuber, D. E. Smith, and F. G. Lemoine (1996), The lunar crust: Global structure and signature of major basins, J. Geophys. Res., 101(E7), 16,841-16,843, doi:10.1029/96JE01246.

O'Connell, R. J., and B. Budiansky (1974), Seismic velocities in dry and saturated cracked solids, J. Geophys. Res., 79(35), 5412-5426, doi:10.1029/JB079i035p05412

Pieters, C. M., S. Tompkins, J. W. Head, and P. C. Hess (1997), Mineralogy of the mafic anomaly in the South Pole-Aitken Basin: Implications for excavation of the lunar mantle, Geophys. Res. Lett., 24(15), 1903-1906, doi:10.1029/97GL01718.

Pieters, C. M., J. W. Head III, L. Gaddis, B. Jolliff, and M. Duke (2001), Rock types of South Pole-Aitken basin and extent of basaltic volcanism, J. Geophys. Res., 106, 28,001-28,022, doi:10.1029/2000JE001414.

Ping, J. S., Q. Huang, J. G. Yan, J. F. Cao, G. S. Tang, and R. Shu (2009), Lunar topographic model CLTM-s01 from Chang'E-1 laser altimeter, Sci. China Ser. G, 52(7), 1105-1114, doi:10.1007/s11433-009-0144-8.

Pohl, J., D. Stoeffler, H. Gall, and K. Ernstson (1977), The Ries impact crater, in Impact and Explosion Cratering: Planetary and Terrestrial Implications, edited by R. B. Merrill, D. J. Roddy, and R. O. Pepin, pp. 343-404, Pergamon, New York

Prettyman, T. H., J. J. Hagerty, R. C. Elphic, W. C. Feldman, D. J. Lawrence, G. W. McKinney, and D. T. Vaniman (2006), Elemental composition of the lunar surface: Analysis of gamma ray spectroscopy data from Lunar Prospector, J. Geophys. Res., 111, E12007, doi:10.1029/ 2005JE002656.

Simmons, G., T. Todd, and H. Wang (1973), The 25-km discontinuity: Implications for lunar history, Science, 182(4108), 158-161, doi:10.1126/ science.182.4108.158
Simmons, G., R. Siegfried, and D. Richter (1975), Characteristics of microcracks in lunar samples, Proc. Lunar Sci. Conf., 6th, 3227-3254.

Simons, M., S. C. Solomon, and B. H. Hager (1997), Localization of gravity and topography: Constraints on the tectonics and mantle dynamics of Venus, Geophys. J. Int., 131, 24-44, doi:10.1111/j.1365-246X.1997. tb00593.x.

Simons, F. J., F. A. Dahlen, and M. A. Wieczorek (2006), Spatiospectral concentration on a sphere, SIAM Rev., 48(3), 504-536, doi:10.1137/ S0036144504445765.

Smith, D. E., et al. (2010), Initial observations from the Lunar Orbiter Laser Altimeter (LOLA), Geophys. Res. Lett., 37, L18204, doi:10.1029/ 2010GL043751.

Solomon, S. C. (1978), The nature of isostasy on the Moon: How big a Pratt-fall for Airy models?, Proc. Lunar Planet. Sci. Conf., 9th, 3499-3511.

Todd, T., D. A. Richter, G. Simmons, and H. Wang (1973), Unique characterization of lunar samples by physical properties, Proc. Lunar Sci. Conf., 4th, 2639-2662.

Toksöz, M. N., F. Press, A. Dainty, K. Anderson, G. Latham, M. Ewing, J. Dorman, D. Lammlein, G. Sutton, and F. Duennebier (1972), Structure, composition, and properties of lunar crust, Proc. Lunar Sci. Conf., 3rd, 2527-2544.

Toksöz, M. N., A. M. Dainty, S. C. Solomon, and K. R. Anderson (1974), Structure of the Moon, Rev. Geophys., 12(4), 539-567, doi:10.1029/ RG012i004p00539.

Tompkins, S., and C. M. Pieters (1999), Mineralogy of the lunar crust: Results from Clementine, Meteorit. Planet. Sci., 34(1), 25-41, doi:10.1111/ j.1945-5100.1999.tb01729.x.

Turcotte, D. L., R. J. Willemann, W. F. Haxby, and J. Norberry (1981), Role of membrane stresses in the support of planetary topography, J. Geophys. Res., 86(B5), 3951-3959, doi:10.1029/JB086iB05p03951.

Wang, H., T. Todd, D. Richter, and G. Simmons (1973), Elastic properties of plagioclase aggregates and seismic velocities in the Moon, Proc. Lunar Sci. Conf., 4th, 2663-2671.

Warren, P. (2001), Porosities of lunar meteorites: Strength, porosity, and petrologic screening during the meteorite delivery process, J. Geophys. Res., 106(E5), 10,101-10,111, doi:10.1029/2000JE001283.

Warren, P. H., and K. L. Rasmussen (1987), Megaregolith insulation, internal temperatures, and bulk uranium content of the Moon, J. Geophys. Res., 92(B5), 3453-3465, doi:10.1029/JB092iB05p03453.

Wieczorek, M. A. (2007), The gravity and topography of the terrestrial planets, Treatise Geophys., 10, 165-206, doi:10.1016/B978-044452748-6/ 00156-5.

Wieczorek, M. A. (2008), Constraints on the composition of the Martian south polar cap from gravity and topography, Icarus, 196, 506-517, doi:10.1016/j.icarus.2007.10.026.

Wieczorek, M. A., and R. J. Phillips (1997), The structure and compensation of the lunar highland crust, J. Geophys. Res., 102(E5), 10,933-10,943, doi:10.1029/97JE00666.

Wieczorek, M. A., and R. J. Phillips (1998), Potential anomalies on a sphere: Applications to the thickness of the lunar crust, J. Geophys. Res., 103(E1), 1715-1724, doi:10.1029/97JE03136.

Wieczorek, M. A., and F. J. Simons (2005), Localized spectral analysis on the sphere, Geophys. J. Int., 162, 655-675, doi:10.1111/j.1365-246X. 2005.02687.x.

Wieczorek, M. A., and F. J. Simons (2007), Minimum-variance multitaper spectral estimation on the sphere, J. Fourier Anal. Appl., 13(6), 665-692, doi:10.1007/s00041-006-6904-1.

Wieczorek, M. A., and M. T. Zuber (2001), The composition and origin of the lunar crust: Constraints from central peaks and crustal thickness modeling, Geophys. Res. Lett., 28(21), 4023-4026, doi:10.1029/ 2001 GL012918.

Wieczorek, M. A., et al. (2006), The constitution and structure of the lunar interior, Rev. Mineral. Geochem., 60, 221-364, doi:10.2138/rmg. 2006.60.3. 